\title{
The metaphor of micin generation in an MSG product commercial
}

\author{
R. Belasunda, M. Tohir \& T. Hendiawan \\ Telkom University, Bandung, Indonesia
}

\begin{abstract}
Advertising, as a persuasive social strategy, is inseparable from the cultural context that surrounds it. The controversy that developed in the community surrounds the use of flavoring ingredients, or micin, and the micin generation that is assumed to be a presentation of the side effects caused by the product. The problems in the advertisement itself are related to the strategy of delivering the message, in this case it is about what is to be conveyed and how the message is interpreted by consumers or viewers of the commercial. Roland Barthes' semiotics with its order of the stages of meaning, i.e., denotation, connotation, myth, and ideology, were used as research methods in this study. The purpose of this research was to find out, through academic studies, how consumers or viewers comprehend and interpret the ideas and messages in commercials.
\end{abstract}

Keywords: commercial, micin, idea, message, micin generation

\section{INTRODUCTION}

The messages in commercials are a persuasive social strategy that intends to influence the way people perceive the purchase and consumption of certain goods. It is often interpreted differently by consumers or viewers. It relates to the cultural context behind them.

The commercial about Sasa food flavoring (micin) as a research object was chosen due to the television commercial some time ago that became a concern on social media (Sasa Melezatkan 2020). This commercial is considered as a breakthrough against the negative stigma of society toward micin (food flavoring) consumption and the micin generation.

\section{THEORETICAL BACKGROUND}

Advertising is a commercial and impersonal way an organization can communicate with consumers and advertise its products to the target audience through mass media (Lee \& Johnson 2018). In its development, advertising evolved into a form of a persuasive social strategy that intends to influence the way people perceive the purchase and consumption of certain goods. Positioning and creating images are the main techniques in producing a strong commercial. Advertisers emphasize not only the product, but also the social significance that is expected to be materialized from purchasing the product (Danesi 2010). Metaphor as a rhetorical strategy used in advertising to provide meaning to a certain product. In context of television, in which advertising serves as a communication media, advertisement creators serve as senders of messages or ideas; advertisement viewers serve as readers of ideas; and an advertisement serves as the medium through which the ideas are being conveyed. As the result of the relations between the verbal and symbolic elements in the advertisement structure, the message in the advertisement is conveyed in a narrative. Advertising on the television media has similar characteristics as film, consisting of its physical structure and constituent elements. The structure of the film consists of shots, scenes, and sequences. The constituent elements consist of narrative elements (story and plot, characterization, main elements, space, time, and story 
information) and cinematic elements (mise-en-scene, cinematography, editing, and sound) (Pratista 2008).

The message in advertising is the main element as object of research in semiotics. A commercial contains three elements: (1) a sign (text), the entity (object) being advertised; (2) context in the form of environment, people or other beings giving meaning to objects; and (3) text (in the form of writing) which strengthens the meaning (anchoring) (Piliang 2010). In the text significance, Barthes in Thwaites and Davis (2009) divided it into denotation and connotation order. Denotation appears to be something after true meaning, with a strong relationship between the signifier and the signified. The connotation, as the second order of significance of the text or signifier, appears as a rather less tangible, imaginary, or illusory meaning. Next, is the myth - the second stage of signification - which constitutes of a way of thinking of a particular culture toward some matters, a manner to conceptualize or comprehend matters (Fiske 2007), and ideology as an illusionary belief in the form of pseudo-ideas and pseudo-awareness (Fiske 2007).

\section{RESULT AND DISCUSSION}

The television advertisement Welcome Back Micin SWAG Generation was the object of the research conducted by the author. This is a commercial for an MSG (Monosodium Glutamate) product from the Sasa brand from PT Sasa Inti, the commercial has been broadcasted on television since early 2020, lasting for 59 seconds of duration (Sasa Melezatkan 2020). The analysis of MSG Sasa's commercial text was carried out toward the narrative and cinematic elements as a sign and sign systems. Text analysis was performed based on narrative, text elements, and cinematic elements.

The results of the text analysis denotatively showed that these commercials used the personification metaphor, wherein the Sasa's food flavoring product (MSG) was represented as micin swag generation's people. MSG which stands for Monosodium Glutamate is identified with Micin Swag Generation. The text element and narrative construction of the commercial were used to build the new comprehension and significance about the product.

Table 1. Text analysis: visual, film semantics, and meaning units.

\begin{tabular}{|c|c|c|c|}
\hline No & Visual Narrative & $\begin{array}{l}\text { Narrative and Text Element } \\
\text { (Object, Context, Anchoring) }\end{array}$ & $\begin{array}{c}\text { Cinematic Elements and } \\
\text { Meaning Units }\end{array}$ \\
\hline 1 & & $\begin{array}{l}\text { Object: a group of people in the } \\
\text { room. } \\
\text { Context: swag generation's } \\
\text { socializing space }\end{array}$ & $\begin{array}{l}\text { Subjective camera angle, } \\
\text { straight camera angle } \\
\text { viewpoint. } \\
\text { The swag generation's } \\
\text { closeness and relaxed } \\
\text { atmosphere }\end{array}$ \\
\hline 2 & & $\begin{array}{l}\text { Object: two swag generation } \\
\text { girls holding a flag outside the } \\
\text { room. } \\
\text { Context: swag generation's } \\
\text { socializing space } \\
\text { Anchoring: We are MSG }\end{array}$ & $\begin{array}{l}\text { Subjective camera angle, } \\
\text { straight camera angle } \\
\text { viewpoint, and it used } \\
\text { symmetric composition. } \\
\text { The MSG group's liberty } \\
\text { and identity. }\end{array}$ \\
\hline 3 & & $\begin{array}{l}\text { Object: a girl holding a } \\
\text { megaphone } \\
\text { Context: a room with a plastic } \\
\text { background } \\
\text { Anchoring: We speak outloud. }\end{array}$ & $\begin{array}{l}\text { Subjective camera angle, } \\
\text { straight angle camera } \\
\text { viewpoint, and using } \\
\text { symmetric composition. } \\
\text { The declaration of } \\
\text { identity and existence. }\end{array}$ \\
\hline
\end{tabular}




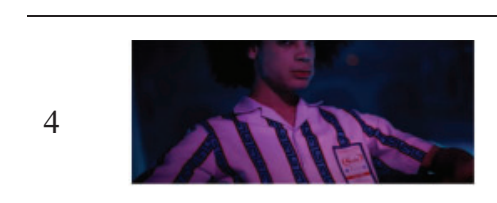

Object: a young man in a room

Context: a closed room

Anchoring: the Sasa's product banding

Object: a young man walks upon the wall

Context: doing parkour
Subjective camera angle, straight angle, close-up camera viewpoint

The declaration of identity.

Subjective camera angle, low angle camera viewpoint

Traversing the obstacles efficiently and as quickly as possible

Subjective camera angle, straight angle camera viewpoint, and using symmetric composition.

Breaking through the boundary together.

Anchoring: We break boundaries

Routine

\section{Subjective camera angle, high angle camera viewpoint, and using over shoulder \\ Object: a woman slicing vegetables \\ Context: moving from the} kitchen to an open space

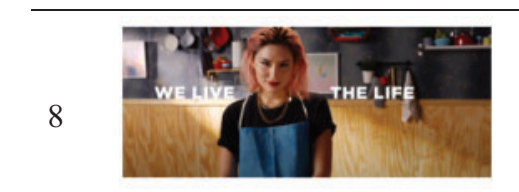

Object: a woman in thekitchen

Context: moving from the kitchen to an open space and the costume changed.

Anchoring: We live the life

Subjective camera angle, low angle camera viewpoint

Breaking through the boundary

Object: white text

Subjective camera angle, Context: a dark lane in a building

Anchoring: We follow our passion straight angle camera viewpoint, and using symmetric composition.

Moving, affirmation.

Object: two young women confidently crossing the road

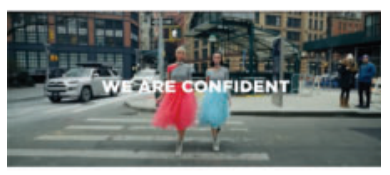
Context: public space Anchoring: We are confident

Subjective camera angle, straight angle camera viewpoint, and using symmetric composition.

Confident.

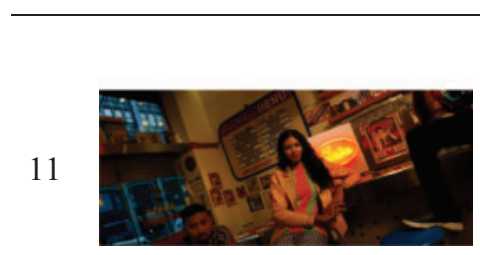

Object: a group of people in a room

Context: swag generation's socializing space

Anchoring: the Sasa's product banding

Subjective camera angle, low angle camera viewpoint, dynamic, neutral screen direction.

The swag generation's closeness and relaxed atmosphere with the product's identity. 


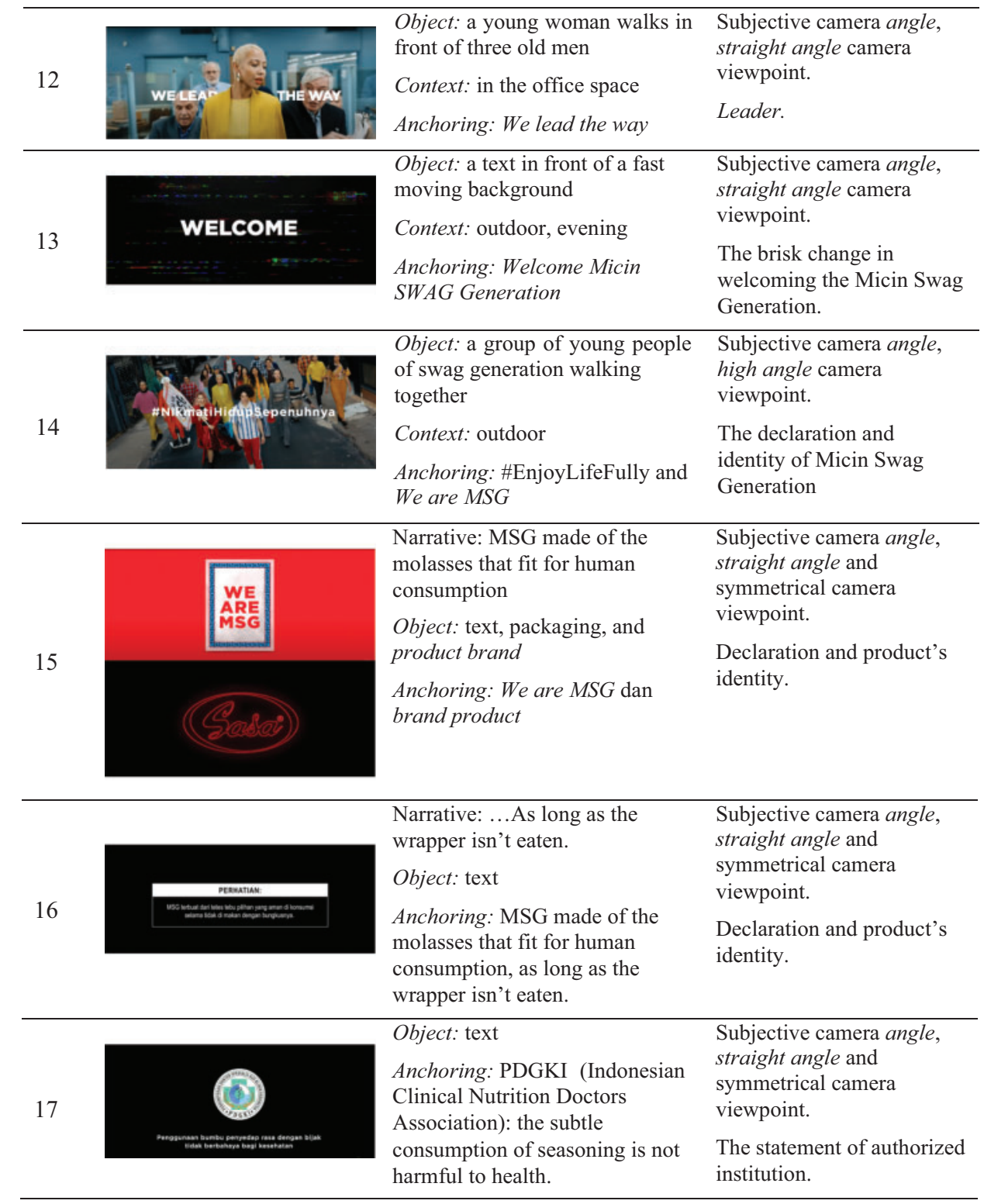

Meanwhile, connotatively it opened up possibilities for dialectical interpretation of messages related to the use of the Micin Swag Generation tagline. Micin generation and swag generation are included in Generation Z, whose characteristics are varied. The swag generation is more likely to be considered to have positive values, while the micin generation was given a negative stigma. The word swag is another word for cool or gangster fashion style. Swag is assumed as an acronym of "style with a little bit gangsta". The micin generation, however, is used to judge the strange, unearthly, unreasonable, difficult to understand, love to show off on social media, and oblivious 
behavior. The micin generation is assumed to be a generation that has consumed too much micin or MSG, as if their level of intelligence is decreased.

The results of the myth analysis relating to the positive values in the Generation $\mathrm{Z}$ characteristics are: (a) confidence in expressing opinions; (b) mastering technology and having the potential to lead in the future; and (c) like social activities and enjoy life. Sasa's MSG products delivered an ideology of pseudo-awareness through a metaphorical narrative that represents the positive values of micin swag generation through the products offered.

\section{CONCLUSION}

Based on the results, it can be concluded that there is a mythical dialectic of positive values in the cultural system and values represented in the advertisment of Sasa's MSG products. Through the narrative of personification and metaphor, the commercial of the very product offers an ideology of pseudo-awareness to the consumers, wherein the product is a representation and is only identified by positive values of the micin swag generation. These commercials formalize a pseudo-awareness that by consuming the product, people can obtain (only) the positive values of the micin swag generation, and put aside the negative stigma of society toward the micin generation.

\section{REFERENCES}

Danesi, M. 2010. Pesan, Tanda, dan Makna. Yogyakarta: Jalasutra.

Fiske, J. 2007. Cultural and Communication Studies. Yogyakarta: Jalasutra.

Lee, M. and Johnson, C. 2018. Prinsip-Prinsip Pokok Periklanan Dalam Perspektif Global. Jakarta: Kencana Prenada Media Group.

Melezatkan, S. 2020. Welcome Back Micin Swag Generation, Youtube.

Piliang, Y.A. 2010. Hipersemiotika: Tafsir Cultural Studies Atas Matinya Makna. Yogyakarta: Jalasutra.

Pratista, H. 2008. Memahami Film. Yogyakarta: Homerian Pustaka.

Thwaites, T. and Lloyd Davis, W.M. 2009. Introducing Cultural And Media Studies. Yogyakarta: Jalasutra. 